\title{
High Sensitive C Reactive Protein in Sudanese Type 2 Diabetic Patients
}

\section{Hala Abdalazeem Aljack (PhD) ${ }^{1,2}$, Omer Fadul Edris $(\mathrm{PhD})^{3}$, Amar Mohamed Ismail (PhD) $)^{3}$}

${ }^{1}$ Department of Clinical Chemistry, Faculty of Medical Laboratory Science, Omdurman Islamic University, Khartoum-Sudan

${ }^{2}$ Department of Clinical Chemistry, Faculty of Medical Laboratory Science, Al-Neelain University, Khartoum-Sudan

${ }^{3}$ Department of Biochemistry and Molecular Biology, Faculty of Science and Technology, AlNeelain University, Khartoum-Sudan

Corresponding Author: Hala Abdalazeem Aljack; Department of Clinical Chemistry, Omdurman Islamic University, Faculty of Medical Laboratory Science, Alshigla street, Khartoum, 11111, Sudan. Tel: 00249915503549 Fax: 382

email:

hala.abdalazeem@yahoo.com

Received 21 February 2019

Accepted 12 May 2019

Published 28 June 2019

Production and Hosting by Knowledge E

(c) Hala Abdalazeem Aljack et al. This article is distributed under the terms of the Creative Commons

Attribution License, which permits unrestricted use and redistribution provided that the original author and source are credited.

Editor-in-Chief:

Prof. Mohammad A. M. Ibnouf

\section{Abstract}

Background: Researchers proved the association between inflammatory condition, high sensitive $\mathrm{C}$ reactive protein (hs-CRP), and cardiovascular diseases (CVDs) in type 2 diabetes mellitus (DM). Therefore, this study aimed to assess the hs-CRP level in type 2 DM patients and their relation to diabetes cardiovascular complications.

Materials and methods: In a case-control study, 205 previously diagnosed type 2 DM patients and 100 controls were included. Serum high Sensitive C Reactive Protein (hs-CRP) was estimated immune-turbidimetrically using Cobas $\mathrm{C}-311^{\circledR}$ fully automated analyzer. Also, triglyceride (TG), total cholesterol (TC), high-density lipoprotein (HDL-C), and low-density lipoprotein (LDL-C) were measured.

Results: Type 2 DM patients had an increased level of hs-CRP ( $p$-value 0.020). Females had higher levels of hs-CRP, TC, HDL-C, and LDL-C than males ( $p$-value 0.005 , $0.000,0.000$, and 0.000 , respectively). Moreover, patients who received statin drugs had decreased levels of hs-CRP, TC, and LDL-C ( $p$-value 0.030, 0.000, and 0.000, respectively). The correlation analysis revealed hs-CRP correlates positively with BMI (r: 0.56, $P$-value 0.000).

Conclusion: The data showed that type 2 DM patients had higher hs-CRP. Moreover, hs-CRP positively associated with BMI. Therefore, obesity might be related to CVDs in type 2 DM patient.

Keywords: High sensitive C reactive protein, cardiovascular diseases, type 2 DM, obesity, Sudan.

\section{Introduction}

Diabetes mellitus (DM) is a chronic metabolic disorder, characterized by hyperglycemic S OPEN ACCESS 
insulin action. [1-3]. Recently, DM become the most common chronic disorder, (4) with increasing prevalence worldwide (5). It was estimated that 425 million people had DM in 2017, and the number is expected to rise to 629 million by 2045 [6]. In Sudan, the prevalence of DM is rising from 9.3\% in 2010 to $10.6 \%$ in four states in 2013 [7].

Type 2 diabetes mellitus is a complex condition, results from the resistance of insulin action combined with impaired pancreatic function [8]. If left uncontrolled, Type 2 DM can cause chronic microvascular and macrovascular complications [9]. Some previous studies confirmed that Type 2 DM gradually causes chronic low-grade inflammation, which plays a vital role in the progression of diabetic complications [10].

Type 2 DM patients are at a high risk to develop CVDs, and the risk increased when patients suffer from nephropathy [11]. The CVDs are observed to increase in type 2 DM with elevated inflammatory markers [12]. The inflammatory marker hs-CRP is a pentameric protein synthesized by hepatic cells under the control of cytokines [11]. It has been identified as a reliable predictor marker for CVDs [13-15]. Previous studies documented that, diabetic patients undergo high serum hs-CRP level [16], that lead to the activation of inflammatory pathways and progression of CVD [17, 18]. Accordingly, this study was conducted to determine whether the hs-CRP is associated with CVDs in type 2 DM patients.

\section{Materials and Methods}

This case-control study was conducted in the Military Hospital at Khartoum state during period from 2015 to 2019. Randomly 205 type 2 DM patients (111 females and 94 males), and 100 apparently healthy control matched in age and gender were selected. DM patients with inflammatory, liver, and/or renal diseases were excluded. After written informed consents, $5 \mathrm{ml}$ venipuncture blood was collected. The study was approved by the local committee of Al-Neelain University, Sudan (issued in May 2015).

\subsection{Measurement of BMI}

Body mass index (BMI) was calculated using (weight $\mathrm{kg} / \mathrm{hight} \mathrm{m}^{2}$ ) formula. 


\subsection{Measurement of hs-CRP}

Serum level of hs-CRP were measured by Cobas C-311 ${ }^{\circledR}$ (Roche Diagnostics, Germany) using the Particle enhanced immunoturbidimetric method Human CRP agglutinates with latex particles coated with monoclonal anti-CRP antibodies, and then the precipitate was determined turbidimmetrically.

\subsection{Measurement of lipid profile}

Serum TG, TG, and HDL-cholesterol were estimated by Cobas C-311 ${ }^{\circledR}$ automated chemistry analyzer (Roche Diagnostics, Germany).

\subsection{TG measurement}

Using the principle enzymatic colorimetric method which based on complete hydrolysis of triglycerides by lipoprotein lipase to glycerol, followed by oxidation and peroxidation process to form a red dyestuff. The color intensity of the red dyestuff formed is directly proportional to the triglyceride concentration and can be measured photometrically.

\subsection{TC measurement}

Estimation of total cholesterol based on serial enzymatic reactions leads to the formation of red quinone-imine dye, which can be measured photometrically. The color intensity of the dye formed is directly proportional to the cholesterol concentration.

\subsection{HDL-C measurement}

In the presence of magnesium ions, dextran sulfate selectively forms water-soluble complexes with LDL, VLDL, and chylomicrons. The cholesterol concentration of HDLcholesterol is determined enzymatically after the formation of a purple-blue dye. The color intensity of this dye is directly proportional to the cholesterol concentration and is measured photometrically. 


\subsection{LDL-C measurement}

Levels of LDL-C were calculated using the Friedwald equation [19] as follow:

$$
L D L-C=T C-\left(H D L-C+\frac{T G}{5}\right)
$$

\subsection{Statistical analysis}

All statistical analyses were performed using the SPSS software (Statistical Package for the Social Sciences) (version 21.0; SPSS Inc.). Descriptive statistic (frequency and percentage) were obtained. Independent $t$-test was employed to compare mean between groups. Pearson's correlation was used to correlate between study parameters and variables. Quantitative variables were demonstrated as mean \pm SD; significant differences were considered as $P$-value $\leq 0.05$.

\section{Results}

The study comprised of 205 Type 2 diabetic patients and 100 subjects as control. The demographic and general characteristics of the population are shown in (Table 1).

The mean level of hs-CRP was significantly increased in the diabetic group $(4.83 \pm 0.42)$ compared with non-diabetic $(3.48 \pm 0.38)$ with $(p$-value 0.020$)$, while there was a significant decrease in HDL-C level in diabetic (39.4 \pm 8.88$)$ compared with nondiabetic group (45.2 \pm 12.4$)$ with ( $p$-value 0.000). Also, the mean levels of TG, TC, and LDL-C, showed insignificant differences when the diabetic group compared to the non-diabetic group (Table 2).

The results of the study showed the mean level of hs-CRP was significantly higher in female $(5.91 \pm 2.61)$ compared with male (3.54 \pm 2.55$)$ with ( $p$-value 0.005). Furthermore, the lipid profile results showed a significant increase in TC, HDL-C, and LDL-C mean levels in female compared with male ( $p$-value 0.000) as shown in (Table 3 ).

Patients group who take cholesterol-lowering agent (statin) had significantly lower levels of hs-CRP, TC and LDL-C as compared with untreated Patients ( $p$-value 0.030, 0.000 and 0.000 , respectively), while other parameter showed insignificant differences between two groups (Table 4). 
In correlation analysis, hs-CRP level correlates positively with BMI ( $r$ : $0.56 p$-value 0.000), while no correlation observed according to age, duration of disease and lipid profile as in (Table 5).

TABLE 1: General baseline characteristics of patients and control groups.

$\left.\begin{array}{l|c|c|}\hline \text { Characteristics } & \text { Diabetic group } & \text { Non-diabetic group } \\ \hline \text { BMI } & 28.0 \pm 4.60 & 25.8 \pm 4.66 \\ \hline \text { Control of Diabetes } & \begin{array}{c}\text { Controlled: } 64(31.2 \%) \\ \text { Uncontrolled: } 141(68.8 \%)\end{array} & - \\ \hline \text { Education status } & \text { Low: } 36(18 \%) & \\ & \text { Moderate: } 132(65 \%) \\ \text { High: } 35(17 \%) & \text { Low: } 33(33 \%) \\ \hline \text { Life style } & \text { Low: } 69(35.0 \%) & \text { High: } 15(15 \%)\end{array}\right)$

TABLE 2: Compersion of serum hs-CRP and lipid profile in diabetic and non-diabetic groups.

Parameter
hs-CRP (mg/l)
TG (mg/dl)
T.Cholestrol (mg/dl)
HDL-Cholestrol (mg/dl)
LDL-Cholestrol (mg/dl)

\begin{tabular}{|c|}
$\begin{array}{c}\text { Diabetic group } \\
\text { (Mean } \pm \text { SD) }\end{array}$ \\
$4.83 \pm 0.42$ \\
$117 \pm 48.3$ \\
$171 \pm 33.7$ \\
$39.4 \pm 8.88$ \\
$101 \pm 35.8$
\end{tabular}

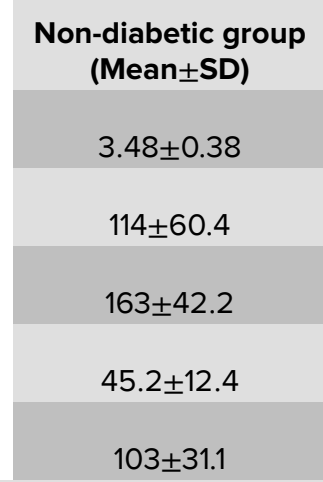

\begin{tabular}{|c|}
\hline P-value \\
\hline 0.020 \\
\hline 0.620 \\
\hline 0.055 \\
\hline 0.000 \\
\hline 0.647
\end{tabular}

The results expressed as (Mean $\pm \mathrm{SD})$ and $P$ value less than 0.05 was considered statistically significant. 
TABLE 3: Compersion of study parameters in patients groups classified according to gender.

Parameters
hs-CRP (mg/l)
TG (mg/dl)
T.Cholestrol (mg/dl)
HDL-Cholestrol (mg/dl)
LDL-Cholestrol (mg/dl)

\begin{tabular}{|c|}
\hline Male $($ Mean $\pm S D)$ \\
\hline $3.54 \pm 2.55$ \\
\hline $119 \pm 60.2$ \\
\hline $150 \pm 39.1$ \\
\hline $37.1 \pm 7.51$ \\
\hline $91.3 \pm 34.5$ \\
\hline
\end{tabular}

Female (Mean \pm SD)
$\begin{gathered}5.91 \pm 2.61 \\ 121 \pm 62.7 \\ 171 \pm 40.1 \\ 41.4 \pm 9.49 \\ 109 \pm 35.0\end{gathered}$

\begin{tabular}{|c|}
\hline P-value \\
\hline 0.005 \\
\hline 0.794 \\
0.000 \\
0.000 \\
0.000
\end{tabular}

The results expressed as (Mean \pm SD) and $P$-value less than 0.05 was considered statistically significant.

TABLE 4: Compersion of study parameters in the patient groups classified according to intake of cholesterollowering agent.

\begin{tabular}{|c|c|c|c|}
\hline Parameters & $\begin{array}{c}\text { Cholesterol-lowering } \\
\text { used (Mean } \pm \text { SD) }\end{array}$ & $\begin{array}{l}\text { Cholesterol-lowering } \\
\text { nonused (Mean } \pm \text { SD) }\end{array}$ & P-value \\
\hline hs-CRP (mg/l) & $3.52 \pm 3.23$ & $4.98 \pm 5.43$ & 0.030 \\
\hline TG (mg/dl) & $121 \pm 69.1$ & $125 \pm 58.8$ & 0.706 \\
\hline T.Cholestrol (mg/dl) & $146 \pm 38.2$ & $176 \pm 40.7$ & 0.000 \\
\hline HDL-Cholestrol (mg/dl) & $38.8 \pm 8.71$ & $39.0 \pm 8.35$ & 0.847 \\
\hline LDL-Cholestrol (mg/dl) & $85.8 \pm 32.1$ & $114 \pm 33.9$ & 0.000 \\
\hline
\end{tabular}

TABLE 5: Pearson's correlation of hs-CRP with BMI, age, duration of disease and lipid profile.

\begin{tabular}{|c|c|c|}
\hline Correlation & $\mathbf{R}$ & P-value \\
\hline BMI & $0.56^{* *}$ & 0.000 \\
\hline age & -0.12 & 0.094 \\
\hline duration of disease & -0.01 & 0.942 \\
\hline TG & -0.020 & 0.778 \\
\hline T.Cholestrol & 0.046 & 0.512 \\
\hline HDL-Cholestrol & -0.043 & 0.544 \\
\hline LDL-Cholestrol & 0.66 & 0.350 \\
\hline
\end{tabular}

(R): Pearson correlation test, (-) negative correlation. A $P$-value of less than 0.05 was considered statistically significant. 


\section{Discussion}

In this study, we found that type $2 \mathrm{DM}$ is prevalent in females than males. The predominance of females with diabetes is attributed to the hormonal effects, the higher ability of the body to store iron and physical inactivity; indeed, most of them were housewives [20]. In our study, the majority of patients are elderly and overweight. Thus postulated combination of genetic predisposition, environmental, nutritional factors, obesity, physical inactivity, stress, and aging [21], might be involved in Sudanese type2 DM. Moreover, patients personal data revealed low to moderate education and socioeconomic status. A previous study observed low educational level correlate with DM, and socioeconomic status inversely associated with DM prevalence [22].

Serum hs-CRP level was significantly higher in type 2 DM patients than non diabetic group. This finding in agreement with the previous study that, pro-inflammatory cytokine hs-CRP was significantly higher in type 2 diabetic patients [23, 24]. Recently, the inflammatory pathway plays a critical role in type 2 pathogenesis, development, and progression of diabetes complications [11]. On the other hand, in accordance with previous reports $[25,26]$, we found that women had higher hs-CRP levels than with men. In fact that gender difference has not yet completely understood, many studies speculated that adiposity, hormones replacement therapy, postmenopausal are associated with higher levels of CRP in women [26].

Furthermore, female type 2 DM patients had higher levels of TC, HDL-C, and LDL-C than the diabetic males which is in line with previous studies [27]. The findings may attributed to the effect of sex hormones and distribution of body fat leading to these differences [27]. Moreover, patients who received Statin treatment revealed lower levels of hs-CRP, TC, and LDL-C. A previous evidence suggest that, therapy with atorvastatin lead to reduced hs-CRP and LDL-C levels in patients with type 2 DM [28].

Likewise, previous reports revealed proportional association between hs-CRP level and BMI [29], our study showed a positive relationship between hs-CRP and BMI. Meanwhile, no correlations noted with lipid profile. Since CRP used to predict CVDs even in patients with low LDL-C, indeed its stability in blood and not affecting by food intake [30].

The limitations of this study are frist the number controls is not equal to patients. Second there are no pre-investigations done to patients, therefore the selection depend on previous clinical investigation. 


\section{Conclusion}

The study concludes that, the hs-CRP level is increased in type $2 \mathrm{DM}$ patients. Females had higher hs-CRP than males. Furthermore, atorvastatin reduces hs-CRP level. Also, hs-CRP correlates positively with BMI Therefore, monitoring of hs-CRP is recommended, especially for females, overweight and obese type 2 DM patients, consequently early intervention.

\section{Acknowledgment}

The authors gratefully acknowledge Dr. Nazik Mahmoud (Specialist of Diabetes and Endocrinology) at the diabetic center of Military hospital for her valuable assistance in this study.

\section{Conflict of Interest}

All authors have declared that no conflict of interest exists.

\section{References}

[1] Khodaeian M, Enayati S, Tabatabaei-Malazy O, Amoli MM. Association between genetic variants and diabetes mellitus in Iranian populations: a systematic review of observational studies. Journal of diabetes research. 2015;2015:21.

[2] Liu J, Li J, Li W-J, Wang C-M. The role of uncoupling proteins in diabetes mellitus. Journal of diabetes research. 2013;2013:7.

[3] Ozougwu J, Obimba K, Belonwu C, Unakalamba C. The pathogenesis and pathophysiology of type 1 and type 2 diabetes mellitus. Journal of Physiology and Pathophysiology. 2013;4(4):46-57.

[4] Shaw JE, Sicree RA, Zimmet PZ. Global estimates of the prevalence of diabetes for 2010 and 2030. Diabetes Res Clin Pract. 2010;87:4-14.

[5] Noor S, Bushara S, Sulaiman A, Elmadhoun W, Ahmed M. Undiagnosed diabetes mellitus in rural communities in Sudan: prevalence and risk factors.. Eastern Mediterranean Health Journal. 2015;21(3):164-70.

[6] Aynalem SB, Zeleke AJ. Prevalence of Diabetes Mellitus and Its Risk Factors among Individuals Aged 15 Years and Above in Mizan-Aman Town, Southwest Ethiopia, 
2016: A Cross Sectional Study. International journal of endocrinology. 2018;2018:1-7.

[7] Balla SA, Ahmed HA, Awadelkareem MA. Prevalence of diabetes, knowledge, and attitude of rural, population towards diabetes and hypoglycaemic event, Sudan 2013. Am J Health Res. 2014;2(6):356-60.

[8] Baranwal JK, Maskey R, Majhi S, Lamsal M, Baral N. Association between level of $\mathrm{HbA1c}$ and lipid profile in T2DM patients attending diabetic OPD at BPKIHS. Health Renaissance. 2017;13(3):16-23.

[9] Moreira TS, Hamadeh MJ. The role of vitamin D deficiency in the pathogenesis of type 2 diabetes mellitus. e-SPEN, the European e-Journal of Clinical Nutrition and Metabolism. 2010;5(4):e155-e65.

[10] Likitesh A, Prabhakar K, Reddy Prasad K. Estimation of high sensitivity c-reactive protein levels as a early marker of diabetic nephropathy. european journal of pharmaceutical and medical research.4(4):315-8.

[11] Khan MI, Usman K, Ashfaq F, Himanshu D, Ali W, Idris M. Association of Hs-CRP and HbA1C with Microalbuminuria in Type-2 Diabetic patients in North India. Biomedical Research. 2012;23(3):380-4.

[12] Patil A, Ganu J. High sensitive C-reactive protein and microalbumin in type 2 diabetes mellitus. Asian Pac J Health Sci. 2014;1(4):319-21.

[13] Sindhu S, Singh HK, Salman MT, Fatima J, Verma VK. Effects of atorvastatin and rosuvastatin on high-sensitivity C-reactive protein and lipid profile in obese type 2 diabetes mellitus patients. Journal of pharmacology \& pharmacotherapeutics. 2011;2(4):261-65.

[14] Mohamed RA, Musa MM, Ismail AM. High Sensitive C-Reactive Protein (hsCRP) as Predictor Marker for Cardiovascular Disease among Vitamin D Deficient Hypertensive Patients. American J Med Med Sci. 2015;5:1-6.

[15] Clearfield MB. C-reactive protein: a new risk assessment tool for cardiovascular disease. Journal-american osteopathic association. 2005;105(9):409-16.

[16] Hayashino Y, Mashitani T, Tsujii S, Ishii H. Serum high-sensitivity C-reactive protein levels are associated with high risk of development, not progression, of diabetic nephropathy among Japanese type 2 diabetic patients: a prospective cohort study (Diabetes Distress and Care Registry at Tenri [DDCRT7]). Diabetes Care. 2014;37(11):2947-52.

[17] Bashir S, Shabbir I, Aasim M. Role of C-reactive protein as a marker for microalbuminuria in type 2 diabetics. Journal of Ayub Medical College Abbottabad. 2014;26(1):32-4. 
[18] Mojahedi MJ, Bonakdaran S, Hami M, Sheikhian MR, Shakeri MT, Aiatollahi H. Elevated serum C-reactive protein level and microalbuminuria in patients with type 2 diabetes mellitus. Iran J Kidney Dis. 2009;3(1):12-6. 27.

[19] Martin SS, Blaha MJ, Elshazly MB, Toth PP, Kwiterovich PO, Blumenthal RS, Jones SR. Comparison of a novel method vs the Friedewald equation for estimating low-density lipoprotein cholesterol levels from the standard lipid profile. Jama. 2013;310(19):20612068.

[20] Ozder A. Lipid profile abnormalities seen in T2DM patients in primary healthcare in Turkey: a cross-sectional study. Lipids in health and disease. 2014;13(1):183.

[21] Kohei K. Pathophysiology of type 2 diabetes and its treatment policy. JMAJ. 2010;53(1):41-6.

[22] Rahmanian K, Shojaei M, Jahromi AS. Relation of type 2 diabetes mellitus with gender, education, and marital status in an Iranian urban population. Reports of biochemistry \& molecular biology. 2013;1(2):64-8.

[23] Momin AR, Pankaja SN, Gouri MB. Albumin/creatinine ratio, as predictor of microalbuminuria, a risk factor for nephropathy in type 2 diabetes mellitus patients. Int. J. Health Sci. Res. 2011;1:34-40.

[24] Valiollah S, Mojtaba E, Vahid I, Ali SM, editors. Association of C Reactive Protein with Insulin Resistance in Type 2 Diabetic. Proceedings of International Conference on Bioscience, Biochemistry and Bioinformatics (ICBBB 2011); 2011.

[25] Mahajan A, Tabassum R, Chavali S, Dwivedi OP, Bharadwaj M, Tandon N, et al. Highsensitivity C-reactive protein levels and type 2 diabetes in urban North Indians. The Journal of Clinical Endocrinology \& Metabolism. 2009;94(6):2123-7.

[26] Qasim AN, Budharaju V, Mehta NN, St Clair C, Farouk S, Braunstein S, et al. Gender differences in the association of $\mathrm{C}$-reactive protein with coronary artery calcium in Type-2 diabetes. Clinical endocrinology. 2011;74(1):44-50.

[27] Zeqollari A, Spahiu K, Vyshka G, Çakërri L. Lipid Profile in Diabetes Mellitus Type 2 Patients in Albania and The Corellation with BMI, Hypertension, and Hepatosteatosis. Journal family medicin community health. 2014;1(4):1018.

[28] Son JW, Kim DJ, Lee CB, Oh S, Song KH, Jung CH, et al. Effects of patient-tailored atorvastatin therapy on ameliorating the levels of atherogenic lipids and inflammation beyond lowering low-density lipoprotein cholesterol in patients with type 2 diabetes. Journal of diabetes investigation. 2013;4(5):466-74.

[29] Amanullah S, Jarari A, Govindan M. Association of hs-CRP with diabetic and nondiabetic individuals. Jordan journal of biological sciences. 2010;3(1):7-12. 
[30] Bandyopadhyay R, Paul R, Basu AK, Chakraborty PP, Mitra S. Study of c reactive protein in type 2 diabetes and its relation with various complications from Eastern India. Journal of Applied Pharmaceutical Science. 2013;3(7):156-9. 